\title{
Is there scope for community health nurses to address lifestyle risk factors? The Community Nursing SNAP Trial
}

\author{
Bibiana C Chan ${ }^{1 *}$, Rachel A Laws², Anna M Williams', Gawaine Powell Davies', Mahnaz Fanaian ${ }^{3}$ and \\ Mark F Harris ${ }^{1 *}$, for the CN SNAP Project Team
}

\begin{abstract}
Background: This paper examines the opportunity and need for lifestyle interventions for patients attending generalist community nursing services in Australia. This will help determine the scope for risk factor management within community health care by generalist community nurses (GCNs).

Methods: This was a quasi-experimental study conducted in four generalist community nursing services in NSW, Australia. Prior to service contacts, clients were offered a computer-assisted telephone interview to collect baseline data on socio-demographics, health conditions, smoking status, physical activity levels, alcohol consumption, height and weight, fruit and vegetable intake and 'readiness-to-change' for lifestyle risk factors.

Results: 804 clients participated (a response rate of $34.1 \%$ ). Participants had higher rates of obesity (40.5\% vs $32.1 \%$ ) and higher prevalence of multiple risk factors (40.4\% vs $29.5 \%)$ than in the general population. Few with a SNAPW (Smoking-Nutrition-Alcohol-Physical-Activity-Weight) risk factor had received advice or referral in the previous $\overline{3}$ months. The proportion of clients identified as at risk and who were open to change (i.e. contemplative, in preparation or in action phase) were $65.0 \%$ for obese/overweight; $73.8 \%$ for smokers; $48.2 \%$ for individuals with high alcohol intake; $83.5 \%$ for the physically inactive and $59.0 \%$ for those with poor nutrition.

Conclusions: There was high prevalence of lifestyle risk factors. Although most were ready to change, few clients recalled having received any recent lifestyle advice. This suggests that there is considerable scope for intervention by GCNs. The results of this trial will shed light on how best to implement the lifestyle risk factor management in routine practice.
\end{abstract}

\section{Background}

Primary health care (PHC) is an appropriate setting in which to address lifestyle risk factors because it is broadly accessible and provides continuing and comprehensive care [1]. Brief lifestyle interventions delivered in PHC have been shown to be effective for smoking cessation [2] and 'at-risk alcohol' consumption [3], and to a lesser extent for diet and physical activity [4-8].

Within PHC, family doctors are the group most often targeted for delivering lifestyle interventions. They, however, face a number of barriers, in particular a lack of

\footnotetext{
* Correspondence: bibi.chan@unsw.edu.au; m.f.harris@unsw.edu.au ${ }^{1}$ Centre for Primary Health Care and Equity, School of Public Health and Community Medicine, University of New South Wales, Sydney NSW 2052, Australia

Full list of author information is available at the end of the article
}

time and funding [9-12]. Generalist community nurses (GCNs) in Australia are also in a good position to offer individual lifestyle intervention, because they (a) often see patients with existing chronic conditions that might benefit from lifestyle change; (b) often have ongoing contact with patients over an extended period of time; (c) mostly see clients in their own homes, and can observe the living environment and involve the wider family/carers in the intervention; and (d) may reach disadvantaged individuals with limited contact with general practice [13,14]. Our previous research has shown that GCNs see lifestyle intervention as appropriate to their role and philosophy of providing holistic care, although some thought the age of their client group limited the scope for lifestyle change [15].

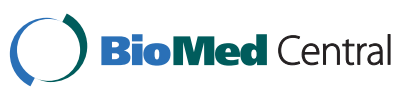

(C) 2012 Chan et al; licensee BioMed Central Ltd. This is an Open Access article distributed under the terms of the Creative Commons Attribution License (http://creativecommons.org/licenses/by/2.0), which permits unrestricted use, distribution, and reproduction in any medium, provided the original work is properly cited. 
Within Australia, GCNs may be either registered or enrolled nurses who are employed by the local Area Health Service. While their role varies depending upon the service in which they work, they predominately provide nursing care in people's homes, including assisting with activities of daily living, wound management, chronic disease care, continence management, palliative care, medication management, disability and dementia care. Patients can be referred following discharge from hospital, referred by their GP or other agencies or self referred.

Although community nurses are well recognised for their role in health education and promotion [16-18], few studies have evaluated their effectiveness in managing lifestyle risk factors as part of routine practice. Two overseas studies have reported positive outcomes of patients receiving advice or counselling on their smoking cessation or alcohol consumption $[19,20]$. However, we are not aware of any study addressing interventions across all five lifestyle risk factors in community nurses' routine practice.

This paper examines the opportunity and need for lifestyle interventions for patients attending GCN services. This will help determine the scope for risk factor management within community health care by GCNs.

\section{Methods}

\section{Study Overview}

This was a quasi-experimental study conducted in four generalist community nursing services in the state of NSW, Australia. This paper reports the findings of baseline data collected from clients prior to contact with the service. The study design and data collection have been described in an earlier publication [21].

\section{Recruitment}

An expression of interest to participate in the trial was sent out to all seven Area Health Services in NSW in 2008. Four generalist community nursing services were selected on the basis of their capacity to participate and recruit sufficient numbers of clients. Clients who were referred to the participating services between September 2009 and September 2010 and met the selection criteria (Additional file 1: Appendix 1) were invited to participate in the study. Potential participants were contacted by phone on the day of referral (wherever possible) by a trained local recruitment officer.

\section{Data Collection}

Those who consented to take part in the study were invited to participate in a computer-assisted telephone interview to collect baseline data. This included information on socio-demographic characteristics, existing health conditions, self-rated physical and mental health based on SF-12 [22], smoking status, physical activity levels [23], alcohol risk categories based on previous research [24], self-report height and weight, and intake of fruit and vegetables [25], along with readiness to change lifestyle risk factors [26] and any previous advice or referral received for existing risk factors.

\section{Analysis}

Descriptive analyses were conducted using SPSS (version 18).

\section{Ethics}

The project was approved by the Human Research Ethics Committees at UNSW and in each Area Health Service.

\section{Results}

\section{Characteristics of clients recruited}

Between September 2009 and September 2010, 804 clients were recruited from 2361 potentially eligible clients (34.1\%) (Figure 1), with similar numbers of males and females. About two-thirds (67.1\%) were 60 years of age or over, and $53.1 \%$ were retired from paid work. Participants were over-represented in the middle and under-represented in the higher quintiles of the Index for Relative Socio-Economic Disadvantage [27]. Few participants spoke a language other than English or were of Aboriginal or Torres Strait Islander descent (Table 1). There were no significant differences in age and gender between those who accepted and those who declined to participate.

\section{Health status, existing conditions and risk factor profile of clients}

Most patients were referred to community nursing services for wound management/dressing (74.6\%); some were referred for medication administration (7.5\%); general care assistance (6.5\%); incontinence care (3.0\%) and other (8.5\%). A total of $61.6 \%$ of clients rated their own health as 'good, very good or excellent' compared with $84.9 \%$ in the general population, perhaps reflecting the fact that $46.9 \%$ had three or more existing health conditions. In relation to mental health, $45.2 \%$ reported that during the past month they had felt 'downhearted or blue' some or all of the time (Table 1). Almost all clients (98.0\%) had at least one lifestyle risk factor and 106 (13.9\%) had at least four (Table 2). There was a higher percentage of individuals with two risk factors $(39.1 \%$ vs $29.5 \%$ ) compared to the $65-84$ year olds in the National Health Survey 2004-5 [28].

\section{Advice and referral of clients identified with lifestyle risk factors}

The majority of participants with a SNAP risk factor had not received any advice or referral in the 3 months 


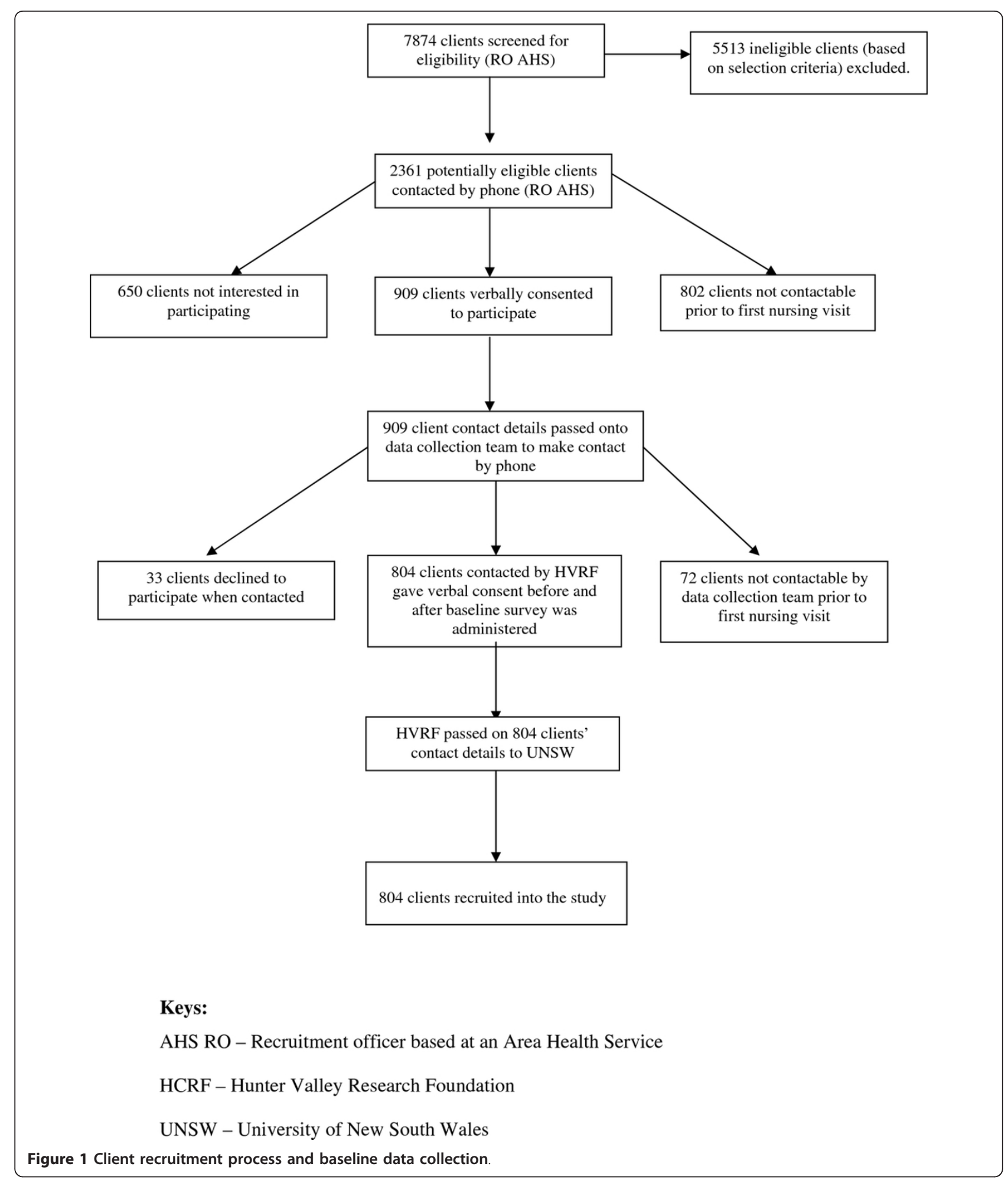

prior to the baseline survey and very few had been provided with a referral (Table 3). The major source of advice at baseline came from the client's GP, hospital doctor or nurse, as well as family and friends. The 'Get
Healthy' phone line [29] was accessed by only two clients. There were five smokers who had used the Quitline in the previous 3 months. About $14.4 \%$ of physically inactive clients attended local exercise programs. 
Table 1 Characteristics of CN SNAP trial clients

\begin{tabular}{|c|c|c|}
\hline Characteristics & Total & \\
\hline Gender & $\mathbf{N}$ & $\%$ \\
\hline Female & 396 & $49.3 \%$ \\
\hline Male & 408 & $50.7 \%$ \\
\hline \multicolumn{3}{|l|}{ Ethnicity } \\
\hline Aboriginal/Torres Strait Islander & 4 & $0.5 \%$ \\
\hline \multicolumn{3}{|l|}{ Language } \\
\hline$\underline{\text { Language other than English }}$ & 35 & $4.4 \%$ \\
\hline \multicolumn{3}{|l|}{ Employment status } \\
\hline Employed & 215 & $26.7 \%$ \\
\hline Unable to work (long-term sickness/disability) & 109 & $13.6 \%$ \\
\hline Retired from paid work & 427 & $53.1 \%$ \\
\hline Other & 53 & $6.6 \%$ \\
\hline \multicolumn{3}{|l|}{ Age $(y r) *$} \\
\hline $30-39$ & 44 & $5.5 \%$ \\
\hline $40-49$ & 78 & $9.7 \%$ \\
\hline $50-59$ & 142 & $17.7 \%$ \\
\hline $60-69$ & 256 & $31.9 \%$ \\
\hline$\geq 70$ & 282 & $35.2 \%$ \\
\hline \multicolumn{3}{|c|}{ Index of Relative Socio-Economic Disadvantage (Postcode not known for 17 participants) } \\
\hline $1^{\text {st }}$ quintile & 148 & $18.8 \%$ \\
\hline $2^{\text {nd }}$ quintile & 146 & $18.5 \%$ \\
\hline $3^{\text {rd }}$ quintile & 285 & $36.2 \%$ \\
\hline $4^{\text {th }}$ quintile & 110 & $14.0 \%$ \\
\hline $5^{\text {th }}$ quintile & 99 & $12.6 \%$ \\
\hline \multicolumn{3}{|c|}{ Self-rated health status (How would you rate your health?) } \\
\hline Poor & 308 & $38.3 \%$ \\
\hline Good, very good or excellent & 494 & $61.6 \%$ \\
\hline \multicolumn{3}{|c|}{ Self-rated mental health status (Have you felt downhearted or blue during the past month?) } \\
\hline A little or none of the time & 440 & $54.8 \%$ \\
\hline A good bit to some of the time & 260 & $32.3 \%$ \\
\hline Most to all of the time & 1023 & $12.7 \%$ \\
\hline \multicolumn{3}{|l|}{ Health conditions } \\
\hline Hypertension (HT) & 395 & $49.1 \%$ \\
\hline Arthritis & 277 & $34.5 \%$ \\
\hline High cholesterol & 239 & $29.7 \%$ \\
\hline Cancer & 213 & $26.5 \%$ \\
\hline Other & 208 & $25.9 \%$ \\
\hline Diabetes & 185 & $23.0 \%$ \\
\hline Depression & 132 & $16.4 \%$ \\
\hline Heart disease & 132 & $16.4 \%$ \\
\hline Anxiety & 105 & $13.16 \%$ \\
\hline Asthma & 104 & $12.9 \%$ \\
\hline Respiratory & 75 & $9.3 \%$ \\
\hline Thrombosis & 73 & $9.18 \%$ \\
\hline Stroke & 28 & $3.58 \%$ \\
\hline
\end{tabular}

Two participants did not disclose their age and two rated their health and mental health status as 'don't know'. 
Table 2 Frequency of individuals with SNAPW risk factors and total number of risk factors

\begin{tabular}{|c|c|c|c|}
\hline No. of SNAPW risk factors & $\begin{array}{c}\mathrm{N}=804 \\
\text { age range: } 30-80 \mathrm{yr}\end{array}$ & \multicolumn{2}{|c|}{$\begin{array}{l}\text { National Health Survey 2004-5 } \\
65-84 \mathrm{yr}\end{array}$} \\
\hline no risk & $9(1.1 \%)$ & \multicolumn{2}{|c|}{$3.9 \%$} \\
\hline physical limitation otherwise no risk & $8(1.0 \%)$ & & \\
\hline 1 risk only \# & $147(18.3 \%)$ & \multicolumn{2}{|c|}{$19.4 \%$} \\
\hline 2 risks \# & $325(40.4 \%)$ & \multicolumn{2}{|c|}{$29.5 \%$} \\
\hline 3 risks\# & $216(26.9 \%)$ & \multicolumn{2}{|c|}{$27.2 \%$} \\
\hline 4 risks\# & $90(11.3 \%)$ & \multicolumn{2}{|c|}{$14.2 \%$} \\
\hline 5 risks\# & $9(1.1 \%)$ & \multicolumn{2}{|c|}{$5.8 \% \S$} \\
\hline \multicolumn{4}{|l|}{ \# excluding major physical limitation; $§ 5+$ risks } \\
\hline \multirow[t]{2}{*}{ Profile of risk factors } & & \multicolumn{2}{|c|}{ National Health Survey 2004-5 } \\
\hline & age range: $30-80 \mathrm{yr}$ & $55-64$ yr & $65-74 y r$ \\
\hline$<2$ serves of fruit $(n=801)$ & $336(41.9 \%)$ & $35.5 \%$ & $33.5 \%$ \\
\hline$<5$ serves of veg $(n=796)$ & $672(84.4 \%)$ & $80.1 \%$ & $84.4 \%$ \\
\hline$<7$ serves of fruit \& veg $(n=795)$ & $624(78.5 \%)$ & Not available & Not available \\
\hline At risk drinking $(n=804)$ & $297(36.9 \%)$ & $15.5 \%$ & $10.4 \%$ \\
\hline Smokers $(n=802)$ & $138(17.2 \%)$ & $17.2 \%$ & $10.5 \%$ \\
\hline Overweight $(O W)(n=785)$ & $263(33.5 \%)$ & $38.3 \%$ & $35.8 \%$ \\
\hline Obese $(n=785)$ & $318(40.5 \%)$ & $22.1 \%$ & $17.9 \%$ \\
\hline OW or obese $(n=785)$ & $581(74.0 \%)$ & $60.4 \%$ & $53.7 \%$ \\
\hline $\begin{array}{l}\text { Unable to engage in physical activity * } \\
(\mathrm{n}=793)\end{array}$ & $375(47.2 \%)$ & & \\
\hline \multirow[t]{2}{*}{ Able to engage in physical activity but inadequate $(n=418)$} & $211(50.5 \%)$ & $35.0 \%$ & $36.3 \%$ \\
\hline & Low exercise level & $34.7 \%$ & $33.0 \%$ \\
\hline
\end{tabular}

The 2009 National Guidelines for Alcohol Consumption is available at: http://www.health.gov.au/internet/alcohol/publishing.nsf/Content/guide-adult The National Health Survey 2004-5 followed the old national guidelines, making direct comparisons problematic.

* those with major physical limitations which (a) limited their ability to engage in physical activity a lot and (b) estimated to last for more than 4 weeks or unsure.

The proportion of patients who had risk factors and who were open to change (i.e. contemplative, in preparation or in action phase) were $65.0 \%$ of the obese or overweight, $73.8 \%$ of the smokers, $48.2 \%$ of those with at risk alcohol intake, $83.5 \%$ of those physically inactive and $59.0 \%$ of those with poor nutrition. The proportion of these who had not received previous advice and referral is shown in Table 4. This group represents those for whom advice by the GCN would be most needed. Three quarters of those at risk for low physical activity were in this category, as were approximately half of those at risk for the other risk factors.

\section{Discussion}

This sample of individuals referred to community nurses had a high prevalence of lifestyle risk factors and associated health conditions that could benefit from lifestyle change. Participants had higher rates of obesity (40.5\% compared to $32.1 \%$ ), and were more likely to have multiple risk factors (40.4\% compared to $29.5 \%$ ) than in the population of a similar age at large [30]. Only a small proportion had received lifestyle advice or referral in the previous three months, despite the majority considering or attempting lifestyle change. The proportion of at-risk clients who were considered suitable candidates for intervention (at risk, ready or attempting change without recent advice or referral) was high for all risk factors. The absolute opportunity for intervention was highest for nutrition and physical activity, because of the higher prevalence of these risk factors in this patient group. This suggests that there is a considerable scope for GCNs to address lifestyle risk factors in these clients.

This raises the question of the most appropriate models of lifestyle intervention for community nursing clients. The community nursing SNAP trial will be testing the feasibility and effectiveness of applying the $5 \mathrm{As}$ model of brief lifestyle intervention within the community nursing context [21]. This consists of 1) screening clients for lifestyle risk factors as part of the routine assessment process 2) assessing readiness to change 3 ) providing brief advice tailored to the clients stage of change 4) referring to support services for more intensive interventions if appropriate 5) following up progress at subsequent visits. These baseline findings suggest however that intervening with this group is not going to be easy because of their age and associated co- 
Table 3 SNAP risk factors advice and/or referrals: Multiple responses allowed

\begin{tabular}{|c|c|c|c|c|c|}
\hline Clients at risk & $\begin{array}{l}\text { Inadequate fruit } \& \\
\text { vegetable intake } \\
(<7 \text { serves) } \\
(\mathrm{n}=625)\end{array}$ & $\begin{array}{l}\text { Inadequate physical } \\
\text { activity }(n=211)\end{array}$ & $\begin{array}{l}\text { Smokers } \\
(\mathrm{n}=38)\end{array}$ & $\begin{array}{l}\text { High/risky alcohol } \\
\text { consumption } \\
(\mathrm{n}=297)\end{array}$ & $\begin{array}{l}\text { Obese/over-weight with } \\
\text { inadequate fruit or } \\
\text { vegetable intake* }(n=580)\end{array}$ \\
\hline $\begin{array}{l}\text { No advice or referral } \\
\text { received }\end{array}$ & $521(83.5 \%)$ & $183(86.7 \%)$ & $104(75.4 \%)$ & 279 (93.9\%) & $481(82.92 \%)$ \\
\hline Received advice & $85(13.6 \%)$ & $22(10.4 \%)$ & $26(18.8 \%)$ & $15(5.1 \%)$ & $86(14.8 \%)$ \\
\hline Received referrals & $50(8.0 \%)$ & $12(5.7 \%)$ & 19 (13.8\%) & $7(2.4 \%)$ & $54(9.3 \%)$ \\
\hline $\begin{array}{l}\text { Received both advice } \\
\text { and referrals }\end{array}$ & $32(5.1 \%)$ & $6(2.8 \%)$ & $11(8.0 \%)$ & $4(1.3)$ & $32(5.5 \%)$ \\
\hline Source of advice & $\begin{array}{l}\text { Multiple responses } \\
\text { allowed }\end{array}$ & Multiple responses allowed & $\begin{array}{l}\text { Multiple } \\
\text { responses } \\
\text { allowed }\end{array}$ & $\begin{array}{l}\text { Multiple responses } \\
\text { allowed }\end{array}$ & Multiple responses allowed \\
\hline GP/practice nurse & $30(4.8 \%)$ & $9(4.7 \%)$ & 19 (13.8\%) & 7 (2.4\%) & $33(5.7 \%)$ \\
\hline Community nurse & $3(0.5 \%)$ & $1(0.5 \%)$ & $1(0.7 \%)$ & 0 & $3(0.5 \%)$ \\
\hline $\begin{array}{l}\text { Hospital doctor/ } \\
\text { nurse }\end{array}$ & $31(5.0 \%)$ & $4(1.9 \%)$ & $12(8.7 \%)$ & $5(1.7 \%)$ & $27(4.7 \%)$ \\
\hline Family \& friends & $30(4.8 \%)$ & $9(4.3 \%)$ & $13(9.4 \%)$ & $8(2.7 \%)$ & $30(5.2 \%)$ \\
\hline Dietitian & $43(6.9 \%)$ & $4(1.9 \%)$ & 0 & $1(0.3 \%)$ & $41(7.1 \%)$ \\
\hline $\begin{array}{l}\text { Get Healthy phone- } \\
\text { line }\end{array}$ & $1(0.2 \%)$ & $1(0.5 \%)$ & 0 & 0 & $1(0.2 \%)$ \\
\hline Exercise physiologist & $3(0.5 \%)$ & $1(0.5 \%)$ & 0 & 0 & $3(0.5 \%)$ \\
\hline Quitline & 0 & 0 & $4(2.9 \%)$ & 0 & 0 \\
\hline $\begin{array}{l}\text { Drug \& alcohol } \\
\text { counsellor }\end{array}$ & 0 & 0 & $1(0.7 \%)$ & $3(1.0 \%)$ & 0 \\
\hline $\begin{array}{l}\text { Local exercise } \\
\text { program/gym }\end{array}$ & $6(1.0 \%)$ & $4(1.9 \%)$ & 0 & 0 & $7(1.2 \%)$ \\
\hline
\end{tabular}

morbidities, with almost half having three or more conditions. Participants were also more than twice as likely to report suffering from depression, compared to those in the 2007 National Survey of Mental Health and Wellbeing $[31,32]$. This is consistent with the finding that depression is a common co-morbidity with chronic disease conditions or multiple lifestyle risk factors [32,33].

It will be important to provide appropriate levels of support at the practitioner and service level to enable lifestyle risk factor management to be provided as part of routine practice. Our previous research with community health staff suggested that clinicians' views and perceptions can influence the extent to which they intervene to address lifestyle risk factors. We found that lifestyle risk factor management practices reflect clinician beliefs about whether they should and can address lifestyle issues. Clinician beliefs about their capacity for risk factor management reflected their views about selfefficacy, role support, and the fit between risk factor management ways of working [15,34]. It is important, therefore, to address community nurse attitudes in order to improve the delivery of lifestyle interventions to clients. It is also imperative to provide them with the necessary training (such as assess SNAPW risks and readiness to change, conduct motivational interviewing, assist clients in goal setting and offer the appropriate level of intervention) to boost their confidence in engaging in these tasks.

Many of the participants in this sample were discharged from hospital or recovering from post-surgical wounds or other illness. Their GPs might not have an opportunity to offer advice on lifestyle risk factor management yet. The process of recovery can create both opportunities and barriers for risk factor interventions. On the one hand, clients are likely to be focused on their health and on regaining normal functioning. This provides opportunities for staff at different stages of care (hospital doctors, community nurses and GPs) to support lifestyle change. On the other hand, the other demands of self-care and managing illness may overshadow lifestyle changes, and any changes that are made might not be sustained once previous health is restored.

For the minority of participants who recalled having received advice or referral, GPs and hospital doctors were the main sources of advice. GPs are often considered the 'front line' for risk factor interventions in primary health care. The incidence of recall of any recent advice from GPs was only $2.4 \%$ for alcohol 
Table 4 Opportunity for lifestyle intervention among clients referred to community nurse teams

\begin{tabular}{|c|c|c|c|c|c|c|c|c|}
\hline \multirow[t]{3}{*}{ Risk Factors } & \multirow{3}{*}{$\begin{array}{l}\begin{array}{l}\text { Number of } \\
\text { clients } \\
\text { identified as } \\
\text { at risk }{ }^{*}\end{array} \\
\text { A }\end{array}$} & \multicolumn{5}{|c|}{ Stages of Readiness to Change } & \multirow{3}{*}{$\begin{array}{l}\text { Percentage of clients } \\
\text { open to change not } \\
\text { having received advice in } \\
\text { last } 3 \text { months } \\
\text { C/B (\%) }\end{array}$} & \multirow{3}{*}{$\begin{array}{l}\begin{array}{c}\text { Opportunity } \\
\text { for } \\
\text { intervention }\end{array} \\
\text { B/A } \times C / B \\
=C / A(\%)\end{array}$} \\
\hline & & \multirow{2}{*}{$\begin{array}{l}\text { Pre- } \\
\text { contemplative }\end{array}$} & \multicolumn{4}{|c|}{ Open to change } & & \\
\hline & & & Contemplative & $\begin{array}{c}\text { In } \\
\text { preparation }\end{array}$ & $\begin{array}{l}\text { In } \\
\text { action }\end{array}$ & $\begin{array}{l}\text { Percentage of } \\
\text { 'Open to } \\
\text { change' } \\
\text { clients B/A (\%) }\end{array}$ & & \\
\hline $\begin{array}{l}\text { Overweight/ } \\
\text { obese } \\
\text { clients to } \\
\text { lose wt }\end{array}$ & 574 & $2015(35.0 \%)$ & $32(5.6 \%)$ & $55(9.6 \%)$ & $\begin{array}{c}286 \\
(50.2 \%)\end{array}$ & $\begin{array}{c}373 / 574 \\
(65.0 \%)\end{array}$ & $327 / 373(87.7 \%)$ & $\begin{array}{l}327 / 574 \\
(57.0 \%)\end{array}$ \\
\hline $\begin{array}{c}\text { Quit } \\
\text { smoking }\end{array}$ & 137 & $36(26.3 \%)$ & $17(12.4 \%)$ & $12(8.8 \%)$ & $\begin{array}{c}72 \\
(52.6 \%) \\
\end{array}$ & $\begin{array}{c}101 / 137 \\
(73.8 \%) \\
\end{array}$ & 96/101 (95.0\%) & $\begin{array}{l}96 / 137 \\
(70.1 \%) \\
\end{array}$ \\
\hline $\begin{array}{l}\text { Reduce } \\
\text { alcohol } \\
\text { intake }\end{array}$ & 293 & $152(51.9 \%)$ & $7(2.4 \%)$ & $28(9.6 \%)$ & $\begin{array}{c}106 \\
(36.2 \%)\end{array}$ & $\begin{array}{c}141 / 293 \\
(48.2 \%)\end{array}$ & $131 / 141(92.9 \%)$ & $\begin{array}{l}131 / 293 \\
(44.7 \%)\end{array}$ \\
\hline $\begin{array}{l}\text { Increase } \\
\text { physical } \\
\text { activity }\end{array}$ & 208 & $33(15.9 \%)$ & $28(13.5 \%)$ & $50(24.0 \%)$ & $\begin{array}{c}97 \\
(46.0 \%)\end{array}$ & $\begin{array}{c}175 / 208 \\
(83.5 \%)\end{array}$ & $158 / 175(90.3 \%)$ & $\begin{array}{l}158 / 208 \\
(76.0 \%)\end{array}$ \\
\hline $\begin{array}{l}\text { Improve } \\
\text { eating } \\
\text { habits and } \\
\text { nutrition }\end{array}$ & 620 & $252(40.6 \%)$ & $25(4.0 \%)$ & $69(11.1 \%)$ & $\begin{array}{c}274 \\
(44.2 \%)\end{array}$ & $\begin{array}{c}368 / 620 \\
(59.4 \%)\end{array}$ & $318 / 368(86.4 \%)$ & $\begin{array}{l}318 / 620 \\
(51.3 \%)\end{array}$ \\
\hline
\end{tabular}

* excluded those with missing RTC

consumption, $4.7 \%$ for physical activity, $4.8 \%$ for advice and $13.8 \%$ for quitting smoking. This is similar to the ranges reported from studies in general practice [35]. It suggests that there are still missed opportunities for lifestyle advice in primary medical practice. It also means that there are opportunities for GCNs to reinforce these messages at a time when patients are likely to focus more on improving their health.

Our previous research $[36,37]$ demonstrates that lifestyle intervention by GPs is possible in general practice. However there needs to be more coordination in assisting and referring clients should more intensive intervention be required. In particular, more group based programs especially to address diet and weight may be required to achieve effective outcomes [36].

About half of the participants with poor nutrition or who were overweight/obese who recalled receiving advice had seen a dietitian. This is promising, given the evidence for effectiveness of interventions by dietitians [38], and suggests that GCNs may need to coordinate their education and advice with the dietitians whom their clients have seen, on a case-by-case basis or through in-service education. 'Family and friends' formed another important source of advice for all four SNAP risk factors. Social support can be important in initiating as well as maintaining lifestyle changes, and GCNs are well placed to encourage this through their contact with clients and their family/carers at home.
One implication for primary health care is to establish stronger links between providers and services for risk factor management to address varying needs of clients and opportunities at different stages of recovery from surgery or illness. This may need to involve GCNs (limited by the stage at which they see the patient), the general practice (limited by time, practitioners' coaching skills and communication with GCNs) and community based programs (currently limited by availability, accessibility and not being well known by GPs or GCNs). By focusing on illness prevention such as offering SNAPW risk factor lifestyle management could potentially minimise the need for medication or hospitalisation in the future.

A key challenge is that providers and services (GCNs, GPs and community based programs) have different funding models, and traditionally integration of care across these services has been poor [39]. The Australian Government recently funded Medicare Locals (NGOs) that have strong local governance, including broad community and health professional representation and have strong links to Local Hospital Networks, Local Health Districts, local communities, health professionals and service providers including GPs, allied health professionals and Aboriginal Medical Services [40]. Medicare Locals will be responsible for providing better integrated care making it easier for patients to navigate the local health care system and should be well placed to 
coordinate care the management of lifestyle risk factor management.

\section{Limitations}

The data collected relied solely on clients' self-report. This could contribute to inaccurate reporting. However, the use of the computerised assisted telephone interview with software that had a built-in logic to skip questions that were not applicable and probe for more detail when warranted enhanced completion rate and minimised missing data. Social desirability may also contribute to respondents providing answers more favourable than the actual behaviours.

\section{Conclusion}

This paper has reported the baseline prevalence of lifestyle risk factors, readiness to change and previous lifestyle advice and/or referral in clients referred to GCNs. There was a high prevalence of lifestyle risk factors, but also of readiness to change, and few clients recalled having received any recent lifestyle advice. This suggests that there is considerable scope for intervention by GCNs, but that this will need to take account of the age of clients, their state of health and the level of support they require to make changes, with coordination of care with other providers and services likely to be important. The results of this trial will shed some light on how best to implement lifestyle risk factor management in routine practice, and how far this leads to lifestyle change with this group of clients.

\section{Additional material}

Additional file 1: Appendix 1. Selection criteria for participating clients.

\begin{abstract}
Acknowledgements
The authors acknowledge the Centre for Health Advancement, NSW Department of Health, for funding the study, along with the CN SNAP project team (Jayasinghe U, Milat A, Orr N, Buckman S, Partington K, Mitchell A, Smith H, Asquith J, Whittaker R, Hilkmann M, Lisle C, Caines K, Clark S, Dunn S)

\section{Author details}

${ }^{1}$ Centre for Primary Health Care and Equity, School of Public Health and Community Medicine, University of New South Wales, Sydney NSW 2052, Australia. ${ }^{2}$ Prevention Research Collaboration, University of Sydney, Medical Foundation Building, 92 Parramatta Rd, Camperdown NSW 2006, Australia. ${ }^{3}$ Illawarra Health \& Medical Research Institute, Faculty of Medicine, University of Wollongong, Wollongong NSW 2522, Australia.
\end{abstract}

\section{Authors' contributions}

All authors contributed to the study design, writing and reviewing the drafts, and approved the final manuscript. In particular, BC and RAL led the development of data collection tools and processes and BC conducted the statistical analysis.

\section{Competing interests}

The authors declare that they have no competing interests in the conduct of this study.

Received: 29 September 2011 Accepted: 15 March 2012

Published: 15 March 2012

\section{References}

1. Whitlock E, Orleans T, Pender N, Allan J: Evaluating primary care behavioral counseling interventions: An evidence-based approach. Am J Prev Med 2002, 22(4):267-284.

2. Rice VH, Stead LF: Nursing interventions for smoking cessation. Cochrane Database of Systematic Reviews 2008, , 1: CD001188, DOI: 10.1002/14651858. CD001188.pub3.

3. Kaner E, Beyer F, Dickinson H, Pienaar E, Campbell F, Schlesinger C, Heather N, Saunders J, Burnand B: Effectiveness of brief alcohol interventions in primary care. Cochrane Database of Systematic Reviews 2007, , 2: CD004148, DOI:004110.001002/14651858.CD14004148. pub14651853.

4. Team CP: Evaluation of the Counterweight Programme for obesity management in primary care: A starting point for continuous improvement. Brit J Gen Prac 2008, 58(553):548.

5. Lawton B, Rose S, Elley R, Dowell A, Fenton A, Moyes S: Exercise on prescription for women aged 40-74 recruited through primary care: two year randomised controlled trial. BMJ 2008, 337:a2509.

6. Pignone M, Ammerman A, Fernandez L, Orleans T, Pender N, Woolf S, Lohr K, Sutton S: Counseling to promote a healthy diet in adults: a summary of the evidence for the U.S Preventive Services Task Force. Am J Prev Med 2003, 24(1):75-90.

7. Eriksson MK, Franks PW, Eliasson M: A 3-year randomized trial of lifestyle intervention for cardiovascular risk reduction in the primary care setting: the Swedish Björknäs study. PLOS ONE 2009, 4(4):e5195, doi:10.1371/ journal.pone.0005195.

8. Elley C, Kerse N, Arroll B, Robinson E: Effectiveness of counselling patients on physical activity in general practice: a cluster randomised controlled trial. Brit Med J 2003, 326:793-798.

9. Brotons C, Bjorkelund C, Bulc M, Ciurana R, Godycki-Cwirko M, Jurgova E, Kloppe P, Lionis C, Mierzecki A, Pineiro R, et al: Prevention and health promotion in clinical practice: the views of general practitioners in Europe. Prev Med 2005, 40(5):595-601

10. Young J, Ward J: Implementing guidelines of smoking cessation advice in Australian general practice: opinions, current practice, readiness to change and perceived barriers. Fam Pract 2001, 18:14-20.

11. Vogt F, Hall S, Marteau TM: General practitioners' and family physicians' negative beliefs and attitudes towards discussing smoking cessation with patients: a systematic review. Addiction 2005, 100(10):1423-1431.

12. Fuller T, Backett-Milburn K, Hopton J: Healthy eating: the views of general practitioners and patients in Scotland. Am J Clin Nutr 2003, 77(suppl):1043S-1047S

13. Kemp L, Harris $E$, Comino E: Changes in community nursing in Australia: 1995-2000. J Adv Nurs 2005, 49(3):307-314.

14. Brookes K, Daly J, Davidson P, Hancock K: Community health nursing in Australia: a critical literature review and implications for professional development. Contemp Nurse 2004, 16:195-207.

15. Laws R, Kirby S, Powell Davies G, Williams A, Jayasinghe U, Amoroso C, Harris M: "Should I and can I?": a mixed methods study of clinician beliefs and attitudes in the management of lifestyle risk factors in primary health care. BMC Health Serv Res 2008, 8:44.

16. Runciman $\mathrm{P}$, Watson $\mathrm{H}$, Mclntosh J, Tolson D: Community nurses' health promotion work with older people. J Adv Nurs 2006, 55(1):46-57.

17. Smith K, Bazini-Barakat N: A public health nursing practice model: melding public health principles with the nursing process. Public Health Nurs 2003, 20(1):42-48.

18. Ward B, Verinder G: Young people and alcohol misuse: how can nurses use the Ottawa Charter for Health Promotion? Aust J Adv Nurs 2008, 25(4):114-119.

19. Borrelli B, Novak S, Hecht J, Emmons K, Papandonatos G, Abrams D: Home health care nurses as a new channel for smoking cessation treatment: outcomes from project CARES (Community-nurse Assisted Research and Education on Smoking). Prev Med 2005, 41:815-821. 
20. Pelc I, Hanak C, Baert I, Houtain C, Lehert P, Landron F, Verbanck P: Effect of community nurse follow-up when treating alcohol dependence with acamprosate. Alcohol Alcohol 2005, 40(4):302-307.

21. Laws R, Chan B, Williams A, Powell Davies G, Jayasinghe U, Fanaian M, Harris M: An efficacy trial of brief lifestyle intervention delivered by generalist community nurses (CN SNAP trial). BMC Nursing 2010, 9(4), doi:10.1186/1472-6955-9-4.

22. Ware JEJ, Koskiski M, Keller SD: A 12-item short-form health survey: construction of scales and preliminary tests of reliability and validity. Med Care 1996, 34(3):220-233.

23. Smith B, Marshall A, Huang N: Screening for physical activity in family practice: evaluation of two brief assessment tools. Am J Prev Med 2005, 29(4):256-264.

24. Bush K, Kivlahan D, McDonell M, Fihn S, Bradley K: The AUDIT alcohol consumption questions (AUDIT-C). Arch Intern Med 1998, 158:1789-1795.

25. NSW Health: New South Wales Population Health Survey (HOIST). Centre for Epidemiology and Research, NSW Health Department; 2006.

26. Prochaska J, Velicer W: The transtheoretical model of health behavior change. Am J Health Promot 1997, 12(1):38-48.

27. Australian Bureau of Statistics: Census of Population and Housing: SocioEconomic Indexes for Areas (SEIFA), Australia (Category No. 2033.0.55.001), 2008.

28. Australian Bureau of Statistics: National Health Survey: Summary of Results (Category No. 4364.0) 2004-05. Canberra: Australian Government.

29. Get Healthy. Information \& Coaching service. [http://www.gethealthynsw. com.au/].

30. Australian Institute of Health and Welfare: Chronic diseases and associated risk factors in Australia, 2006. Cat. no. PHE 81. Canberra:: AlHW; 2006.

31. Australian Bureau of Statistics: 2007 National Survey of Mental Health and Wellbeing: summary of results. Canberra ABS; 2008

32. Pfaff JJ, Draper BM, Pirkis JE, Stocks NP, Snowdon JA, Sim MG, Byrne GJ, et al: Medical morbidity and severity of depression in a large primary care sample of older Australians: the DEPS-GP project. MJA 2009, 190(7): S75-S80.

33. Clarke DM, Currie KC: Depression, anxiety and their relationship with chronic diseases: a review of the epidemiology, risk and treatment evidence. Med J Australia 2009, 190(7):S54-S60.

34. Laws R, Kemp L, Harris M, Powell Davies P, Williams A, Eames-Brown R: An exploration of how clinician attitudes and beliefs influence the implementation of lifestyle risk factor management in primary healthcare: a grounded theory study. Implementation Science 2009, 4:66.

35. Britt H, Miller GC, Knox S, Charles J, Pan Y, Henderson J, Bayram C, Valenti L, $\mathrm{Ng} \mathrm{A}$, O'Halloran J: General practice activity in Australia 2004-05. AlHW Cat. No. GEP 18. Canberra: Australian Institute of Health and Welfare (General Practice Series No. 18); 2005.

36. Harris MF, Fanaian M, Jayasinghe U, Passey MM, Lyle D, McKenzie S, Powell Davies G: What predicts patient reported GP management of SNAPW behaviours? Aust J of Primary Health 2011 [http://dx.doi.org/10.1071/ PY11024].

37. Schutze H, Rix EF, Laws R, Passey MM, Fanaian M, Harris MF: How feasible are lifestyle modification programs for disease prevention in general practice? Aust J of Primary Health 2011 [http://dx.doi.org/10.1071/PY10106].

38. Thompson RL, Summerbell CD, Hooper L, Higgins JPT, Little PS, Talbot D, Ebrahim S: Relative efficacy of differential methods of dietary advice: a systematic review. Am J Clin Nutr 2003, 77(4):1052S-1057S.

39. Powell Davies G, Perkins D, McDonald J, Williams A: Integrated primary health care in Australia. Int J Integr Care 2009, 9:e95, Accessed on 29-Nov2011 via http://www.ncbi.nlm.nih.gov/pmc/articles/PMC2787230/? tool=pubmed.

40. Australian Government: Establishment of Medicare Locals and better access to after hours care., Accessed on 25-Nov-2011 via http://www. yourhealth.gov.au/internet/yourhealth/publishing.nsf/Content/factsheet-gp01.

\section{Pre-publication history}

The pre-publication history for this paper can be accessed here: http://www.biomedcentral.com/1472-6955/11/4/prepub

doi:10.1186/1472-6955-11-4

Cite this article as: Chan et al:: Is there scope for community health nurses to address lifestyle risk factors? The Community Nursing SNAP Trial. BMC Nursing 2012 11:4.

\section{Submit your next manuscript to BioMed Central and take full advantage of:}

- Convenient online submission

- Thorough peer review

- No space constraints or color figure charges

- Immediate publication on acceptance

- Inclusion in PubMed, CAS, Scopus and Google Scholar

- Research which is freely available for redistribution

Submit your manuscript at www.biomedcentral.com/submit
C Biomed Central 